\title{
El cuerpo de los pecadores en los Milagros de Nuestra Señora de Gonzalo de Berceo
}

\section{The body of sinners in the Milagros de Nuestra Señora by Gonzalo de Berceo}

\author{
Jezabel Koch \\ jeza_koch@hotmail.com \\ Seminario de Edición y Crítica Textual. Instituto \\ de Investigaciones Bibliográficas y Crítica Textual. \\ Universidad de Buenos Aires / CONICET, Argentina
}

Recepción: 30 Octubre 2020

Aprobación: 24 Abril 2021

Publicación: 03 Mayo 2021

Cita sugerida: Koch, J. (2021). El cuerpo de los pecadores en los Milagros de Nuestra Señora de Gonzalo de Berceo. Olivar, 21(33), e094. https://doi.org/10.24215/18524478e094

\begin{abstract}
Resumen: El presente trabajo busca considerar el cuerpo del pecador en los Milagros de Nuestra Señora de Gonzalo de Berceo comprendido desde su humanidad como aquello que se disputan las fuerzas del Bien y del Mal. En efecto, entendido como el contrapunto del santo, no hay cuerpo más humano que el cuerpo del pecador, el cual deviene víctima de los acosos demoníacos, que no hacen otra cosa que usufructuar mal ese espacio que, a fin de cuentas, pertenece a la divinidad. Así pues, el hombre, pero por encima de todo su cuerpo, son concebidos como la apuesta de la batalla entre ambas fuerzas. Y si esta batalla encuentra su lógica en un enfrentamiento cifrado en una disputa jurisdiccional, el cuerpo deviene testimonio inmediato de una realidad trascendental.

Palabras clave: Cuerpo, Pecador, Berceo, Bien, Mal.

Abstract: The current paper inquires into the body of sinners in the Milagros de Nuestra Señora by Gonzalo de Berceo. And does this from a human perspective, considering the body as an element in dispute between Good and Evil. Indeed, the body of sinners (considered as the opposite of the body of saints), the most human body, turns into victim of demonic harassment, resulting in a illegitime use of this property, which belongs to divinity by right. Thus, man, but mostly his body, is the loot sought by both sides. And, in the end, if this battle is understood from a territorial perspective, then the body becomes the immediate testimony of a trascendental reality.
\end{abstract}

Keywords: Body, Sinner, Berceo, Good, Evil.

\section{INTRODUCCIÓN}

Durante la primera mitad del siglo XIII castellano es posible distinguir el resultado de una serie de procesos que de forma simultánea se han venido gestando desde el siglo XII. Entre los más interesantes se encuentra el que supone el pasaje del castellano como lengua vulgar de comunicación a su promoción como lengua de cultura, ligado de modo indisociable a la figura del clérigo letrado, cuya mano gestará los primeros testimonios de producción verbal escrita en lengua romance.

En este contexto, la figura de Gonzalo de Berceo se yergue, en palabras de Rico, como la del "más ilustre entre los clérigos seculares” (1985, p. 136). Dejando a un lado las comparaciones, vale la pena señalar la 
fortuna que supone conservar el testimonio de su nombre y su figura, en la cual se encuentra reunida una profusa obra escrita por entero en castellano bajo la forma métrica de la cuaderna vía. ${ }^{1}$

No resulta en vano subrayar el carácter innovador que atraviesa la figura de Berceo. Pues, en efecto, "[n]uevos, ciertamente, y con decisiva conciencia de modernidad [...] son esos clérigos seculares de la Península" (Rico, 1985, p. 149); así como también nueva es la sociedad en la que se inscriben y sobre la cual operan. Pero, por encima de todo, radicalmente novedosa es su labor, en la que se imbrican "educación latina y expresión romance" (Rico, 1985, p. 147). ${ }^{2}$

Estos señalamientos, no solo ofrecen el marco para una mejor comprensión de la producción berceana, sino que, a su vez, permiten considerar la figura del poeta en lo que en ella hay de disruptivo, muy lejos de la imagen de "clérigo ingenuo" que la crítica tradicional gestó en sus primeros estudios y que la labor de Dutton logró impugnar. ${ }^{3}$

Ahora bien, a poco que nos detenemos en el conjunto de las obras de Berceo un hecho salta a la vista: considerar sus poemas supone el ingreso a una esfera por entero sacra, en la medida en que todas ellas se inscriben en el ámbito de lo sagrado. Y si las Vidas permiten considerar aquellas regiones que se movilizan para formar a un santo, los Milagros ofrecen la oportunidad de abordar su contrapunto, la figura del pecador. Como dice Alvar, un "santo es aquel hombre que tiene algo más que humanidad", pues "[s]i el santo no fuera otra cosa que un hombre de carne y hueso, no sería santo" (1992, p. 40). Pero, lo cierto es que si el santo se eleva por encima de su condición humana, es porque logra encarnar un ideal de perfección cuyo contrapunto se sostiene en la figura del pecador, aquel hombre que parecería limitarse a su condición mortal, a ser, sencillamente, un hombre de carne y hueso. Así pues, el santo y el pecador suponen los márgenes entre los cuales, oscilante, pendula la humanidad.

No obstante, cabe decir que estas dos figuras se inscriben en un marco de comprensión mucho más vasto: la de la siempre disputada batalla entre el Bien y el Mal, entre la Divinidad y Satanás. En efecto, como observa García de la Concha,

el románico contempla la historia del mundo y la vida de cada hombre dentro de ella como una gran batalla entre Dios y el Demonio, y, proyectándola sobre los esquemas culturales de la época, la traduce a términos feudales de vasallaje. (1992)

Lo que interesa aquí subrayar es el hecho de que es el hombre, y más precisamente, su cuerpo, el que se encuentra en medio de esta batalla. Si bien, como expresa Le Goff, aquello que concierne al hombre radica en aceptar o rechazar la gracia salvífica, en ceder o resistir al pecado que lo condena, "el hombre es la apuesta de la batalla en la que se empeñan para su salvación o para su condenación los dos ejércitos sobrenaturales, dispuestos a cada momento a atacarlo o socorrerlo" (1995, p. 17). Así pues, no solo el hombre se encuentra implicado en este enfrentamiento continuo, sino que, como podremos observar, es su propio cuerpo el que estas fuerzas se disputan. En efecto, será en esta lucha permanente entre la Divinidad y el Maligno que el cuerpo devendrá territorio en disputa, espacialidad bien o mal usufructuada, testimonio inmediato de una realidad trascendental.

El santo, entonces, es considerado en la época que nos ocupa la más alta realización humana, y las vitae a ellos dedicadas presentan su cuerpo y su trayectoria vital en términos de ejemplaridad. Y si bien el adoctrinamiento corpóreo cumple un rol fundamental en el camino de santidad emprendido, lo cierto es que también, tras este halo constrictivo que circunda la materia humana, emerge en simultáneo otra realidad, la del cuerpo como garante de acceso a la santidad. Pues, si bien es cierto, como señala Balestrini que el cuerpo en "las vidas de santos, a fuerza de negarlo, castigarlo y exponerlo a sufrimientos, está indisolublemente asociado a la figuración del camino de santidad de los personajes" (2000, p. 270), este sesgo negativo en lo que a la apreciación de la materialidad física se refiere, se matiza de modo sugestivo al considerar, como hace Bynum (1990), que, lejos de ser la negación de lo físico, en la devoción medieval, el control, la disciplina, e incluso la tortura de la carne son su elevación - una horrible pero deliciosa elevación - entre los modos de acceso a lo divino. 
Ahora bien, en contraste con el cuerpo santo, se yergue este otro, reputado quizás, de una menor fortuna: el cuerpo del pecador. Y si bien es cierto que ambas corporalidades - tanto la santa como la pecadora - son concebidas en términos de una territorialidad que se inscribe en el plano terrenal de las posesiones divinas, también lo es que sutiles diferencias caracterizan a una y otra carne, en la medida en que los pecadores no gozan de la misma ecuanimidad que caracteriza a los santos. En efecto, una cosa es el cuerpo santo que presentan las Vidas, y muy otro el cuerpo de los pecadores asistidos por la Virgen.

Y este distingo resulta sugerente, ya que los Milagros de Nuestra Señora de Gonzalo de Berceo reúne una serie de historias milagrosas articuladas en torno a la Virgen María, sin cuya intervención la gracia divina no se hubiese manifestado en la trayectoria vital del pecador. Como señala Baños Vallejo,

[e]l protagonista del milagro literario es el simple pecador, que recibe la ayuda de Dios por pura misericordia. Su vida cambia como consecuencia de la intervención divina, que lo aleja del pecado y lo convierte [...]. Por el contrario, el protagonista del milagro hagiográfico es un santo, alguien cuya vida ha sido consagrada a la virtud, y que recibe la intervención divina como consecuencia de su recto proceder. El prodigio aquí no es un acto misericordioso, sino una gratificación, una prueba de confianza. (2003, p. 72)

Establecida esta distinción entre el santo y el pecador, el estudioso agrega que el enfrentamiento contra el Mal en los textos hagiográficos supone, un episodio que no hace más que corroborar la fortaleza del santo que, ya se sabe, está destinado a la gloria celeste. ${ }^{4}$ En cambio, lo propio de las intervenciones divinas en el caso de los milagros supone una intervención "in extremis, para salvar al pecador de la muerte o de la perdición eterna” (Baños Vallejo, 2003, p. 73). De este modo, nos situaremos en el centro de la batalla entre el Bien y el Mal, en la cual el cuerpo del pecador se yergue en tanto territorio en disputa entre ambas fuerzas.

Resulta consabido que los Milagros de Berceo se inscriben en una vasta tradición europea, conjugando lo que Alvar ha sabido definir como "universalidad y localismo" (1992). En efecto, a lo largo de los siglos XII y XIII es posible constatar nuevos modos de devoción, más ligados con el afecto y con los aspectos humanos de la divinidad, lo que supuso, a su vez, un impacto también en la exaltación al culto de la Virgen María.

Si nos remontamos en el tiempo, cabe decir que, en los textos iniciales del cristianismo primitivo, la Virgen María no comportaba mayor importancia. Su primera mención histórica se encuentra en la Epistola a los gálatas, de San Pablo escrita hacia los años 54 o 57, donde se menciona, simplemente, que Cristo nació de mujer. Recién hacia el año 70, en el Evangelio de San Lucas, aparece cierto desarrollo narrativo de la figura de María como la madre de Jesús - al incluir el episodio de la Anunciación, los momentos previos al nacimiento, el episodio de las bodas de Caná y, finalmente, su presencia en el desarrollo de la pasión al final del Evangelio-.

Si bien, como señala Gerli, con los escritos de San Justiniano y San Ireneo, "la madre de Cristo empieza a incorporarse a un esquema teológico de la salvación y redención cristianas" (2006, p. 20), esta falta de relevancia inicial cobra un giro radical cuando, tras un intenso debate de siglos, María es proclamada "María Theókotos" en el concilio de Efeso, en el año 431. Es decir que allí, María es proclamada "madre de Dios”. En otras palabras, María no es solo la madre de la parte humana de Jesús, sino que, a partir del siglo V, María es concebida como madre de Dios. Y este hecho impactará en su consideración y en su valoración, en términos de una "excepcionalidad" religada, más específicamente, a la idea de "virginidad".

En el siglo VII, san Ildefonso de Toledo (606-667) - a quien Berceo le dedica el milagro con el que se abre la colección, tras el "Prólogo alegórico" - redacta un tratado sobre la virginidad de María a partir del cual pasa a formar parte del dogma que María no es solo la madre de Dios, sino que también es la Virgen María. Esto, como puede apreciarse, impactará en la concepción de su propia "humanidad", comprendida, como se ha dicho, en términos de "excepcionalidad".

El siguiente momento en el desarrollo del culto de la Virgen María supone un salto temporal al siglo XII, y se extiende hasta el momento en que Berceo escribe los Milagros, en donde nos encontramos con una devoción más afectiva y, por encima de todo, más humana. En efecto, como señala Gerli, la naturaleza humana de la Virgen "es el factor decisivo que lleva a San Bernardo a definirla como la mediadora ideal entre los 
hombres y Cristo" (2006, p. 22). Entre los textos más notables, de este monje cisterciense y gran impulsor del culto mariano, cabe mencionar aquellos dos que nos permitirán una comprensión más cabal del modo en que la Virgen es pensada en las colecciones de milagros. El primero es el De Aquaeductu, en el cual San Bernardo delinea la idea de que, siendo Cristo la fuente de toda gracia, es María el canal a través del cual esta gracia divina llega a la humanidad. María resulta ser así la mediadora por excelencia entre lo divino y lo humano - no hace falta decir que es a través de María que Dios se ha hecho hombre - , y entre lo humano y lo divino - pues en su condición de mediadora, los creyentes pueden alcanzar la gracia de Dios-. El otro texto que cabe mencionar es su Sermón séptimo sobre la Natividad, en el que María aparece como abogada de los pecadores, en la medida en que, ante la debilidad humana, no existe abogada mejor ante Dios que su madre. Como puede leerse, el santo declara que

[e]s María quien os ha dado este hermano Cristo. Pero quizá teméis en él la majestad divina, pues aunque se haya hecho hombre, continúa siendo Dios, sin embargo. ¿Queréis tener un abogado cerca de él? Recurrid a María. No hay en ella más que humanidad pura, no solamente porque es pura de toda mácula, sino pura aún en el sentido de que no hay en ella más que la sola naturaleza humana (Saugnieux apud Gerli, 1982, p. 62, las cursivas son nuestras).

La idea que prevalece aquí es que, dado que un hijo no se negaría a los deseos de su madre, María pasa a comprenderse como cobijadora de la humanidad sufriente. Y aunque por evidente, no resulta menos importante decir que la efectividad de estas dos imágenes propias del modelo de piedad bernardino - la de María en tanto canal de gracia, y la de María en tanto cobijadora de la humanidad- se encuentra apuntalando todo el desarrollo de los Milagros berceanos. ${ }^{5}$

Así pues, universalismo, como expresara Alvar (1992), pero también localismo, en la medida en que los Milagros no sólo se inscriben en la devoción popular de la Europa occidental del período, sino que responden, como afirma Gerli, a una "tendencia de la Iglesia hispánica hacia la veneración de la virgen” (2006, p. 21) a la vez que, como ha sugerido Dutton (1980), se imbrican también en el interés concreto de atraer a los peregrinos que se encuentran realizando el Camino de Santiago al cenobio de San Millán.

Acerca de la datación de los Milagros, gracias a referencias internas puede deducirse que el texto fue escrito tras un largo periodo de elaboración. Así, se juzga que Berceo habría comenzado a escribirlos antes de 1246 - debido a que en la cuaderna 325, se menciona a don Tello Téllez de Meneses vivo - , y aún continuaba trabajando en ellos después de 1252 - dado que en la cuaderna 869, se menciona a Fernando el Santo como ya muerto - .

En cuanto a su fuente primaria, la crítica coincide en aceptar como tal una compilación latina de veintiocho milagros, de la cual se conservan dos testimonios manuscritos: el Ms. Thott 128 de la Biblioteca Real de Copenhague y el Ms. 110 de la Biblioteca Nacional de Madrid. ${ }^{6}$ Aunque cabe destacar que no se ha encontrado ningún testimonio que pudiese operar como fuente del "Prólogo alegórico" con el que Berceo abre su colección. ${ }^{7}$

García de la Concha señala que,

mientras la mentalidad moderna contempla tierra y cielo como mundos diferenciados, el hombre medieval funde ambos en un proceso de "general divinización" que, como apunta Saugnieux, se convierte en una "humanización general" [...]: ángeles y demonios, la Virgen y los santos se tornan vecinos familiares y lo milagroso, lejos de constituir algo extraordinario, se multiplica como habitual (1992).

En este contexto de humanización general, el cuerpo no pasa desapercibido. Muy por el contrario, asume un lugar de importancia cabal al devenir el territorio en disputa entre las fuerzas del Bien y el Mal. Desarrollada esta devoción centrada en la humanidad de Cristo, no resulta sorprendente que no solo la salvación del alma suponga una preocupación fundante, sino también, la del cuerpo. Como bien expresa Berceo, la Virgen es "sennora natural, pïadosa vezina, / de cuerpos e de almas salud e medicina" (33cd), por lo cual, servirla supone en parte no solo salvar el alma, sino también, honrar el cuerpo: "Amigos, a tal 
Madre aguardarla devemos: / si a ella sirviéremos nuestra pro buscaremos, / onrraremos los cuerpos, las almas salvaremos, / por pocco de servicio grand gualardón prendremos” $(74){ }^{8}$

\section{El cuerpo y EL Diablo: corporalidades mal uSUfRUCtUADAS}

Pensar en la batalla entre el Bien y el Mal supone desde el comienzo considerar la presencia de los dos bandos mentados, cuyos máximos exponentes serían, la divinidad, por un lado y el Diablo, por el otro. Ahora bien, todo enfrentamiento culmina con la victoria. Y aunque el Bien, desde el esquema Cristiano de la Salvación, ha por siempre ya ganado, lo cierto es que, en el proceso, el Diablo acomete en más de una batalla. Y aquello que disputa, es decir, aquello por sobre lo cual busca la conquista, es sobre un territorio que no le pertenece, pero que en más de una ocasión logra usufructuar indebidamente: los cuerpos de los hombres. Así pues, teniendo en cuenta los tres aspectos que modelan estos enfrentamientos, nos centraremos en este primer apartado en la consideración del diablo en el momento en que se enfrenta a los hombres que no ostentan la pureza de espíritu del santo, en busca de su conquista corporal. Lo cierto es que, desde el momento en que la unidad temática de los Milagros se revela ligada al problema del pecado en todas sus manifestaciones, resulta ineludible la consideración del cuerpo en su relación con las fuerzas del Mal.

Siendo concebido como espacio, como posada, el cuerpo presenta desde el inicio la cuestión central de la jurisdicción, como puede apreciarse en el caso de "El sacristán fornicario".

Desde un primer momento, la importancia del cuerpo queda destacada en el milagro, puesto que el amor profesado por el sacristán a la Virgen se traduce en una serie de movimientos corporales codificados: "querié de corazón bien a Sancta María, / facié a la su statua el enclín cada día” (76cd). Efectivamente, es en esta reverencia en la que se traduce un servicio a la Virgen que a fin de cuentas cifra la rectitud moral del "monge beneíto" (76a): "Facié a la su statua el enclín cada día, / fincava los enojos, dicié: 'Ave María'; / el abbat de la casa dio.l la sacristanía, / ca teniélo por cuerdo e quito de follía" (77).

Y si es por medio del cuerpo que se expresa una rectitud del alma, no sorprende que el Diablo atente contra este mismo espacio, buscando así invertir la ecuación: "El enemigo malo, de Belzebud vicario, / que siempre fue e éslo de los buenos contrario, / tanto pudió bullir el sotil aversario / que corrompió al monge, fízolo fornicario" (78).

Resulta elocuente subrayar, como hace Weiss, el hecho de que el texto latino presente al monje ya en su puesto de sacristán y ya corrupto, mientras que en nuestro poema, recién "[h]aving established the monk's spiritual, moral, and administrative virtues, Berceo sets the Devil to work” (2006, p. 78). ${ }^{10}$ El monje, efectivamente, cae en una conducta desviada, una "mala lavor" (79d) que encuentra en el cuerpo, y en su satisfacción, el espacio por excelencia. No obstante, lo que importa atender es que esta conducta desviada no invalida ni interrumpe aquella sumisión demostrada a la virgen: "Siquier a la exida, siquier a la entrada, / delante del altar li cadié la passada; / el enclín e la Ave teniéla bien usada, / non se li oblidava en ninguna vegada" (80).

Así pues, el cuerpo del sacristán fornicario se revela en su constitutiva inestabilidad, virtuoso y pecador a una vez, vehículo para el pecado, pero también para la salvación. Como señala Weiss, Berceo "casts no doubt on the existence of the moral categories of right and wrong, but his poetry displays a fascination for their point of contact, when the values and ideals that govern actual existence can co-exist or overlap" (2006, p. 29).

Sucede que, en el proceso de sus desvíos, una noche el sacristán cae al río y muere ahogado. Y mientras “yazié en vanno el cuerpo en el río" (85), es sobre el alma sobre la que recaerá la atención ahora y sobre la que se actualizará esta intermitencia, esta superposición que culminará expresándose en términos de una problemática jurisdiccional. En efecto, habiendo muerto durante el pecado, los diablos se disponen a llevarse el alma del sacristán al infierno, en una actitud lúdica que hace que Berceo la homologue a una pelota. No obstante, los ángeles intentan reclamarla, pero el enfrentamiento es ganado por la lógica diabólica: 
[...]

digamos de la alma
vinieron de diaablos
por levarla al váratro,

Mientre que los dīablos

vidiéronla los ángeles,

ficieron los dīablos

que suya era quita,

Non ovieron los ángeles
ca ovo la fin mala
tirar no lis podieron
ovieron a partirse

en qual pleito se vío:

por ella grand gentio,

de deleit bien vazío. (85) la trayén com a pella,

descendieron a ella, luego muy grand querella,

que se partiessen d'ella. (86)

\author{
razón de vozealla, \\ e asin sin falla; \\ valient una agalla, \\ tristes de la vatalla. (87)
}

Si bien el enfrentamiento entre ángeles y diablos culmina en favor de los segundos, la intercesión de la Virgen revierte esta situación. Pudo perderse una batalla, pero nunca la guerra. Lo interesante, no obstante, es que como podremos apreciar, y este ejemplo resulta paradigmático, en los Milagros el enfrentamiento entre el Bien y el Mal impregna la lógica guerrera de tintes jurídicos. Si, por ejemplo, en la Vida de San Millán, el enfrentamiento es literal, y el santo está en guerra con las fuerzas del Mal, aquí, en los Milagros, la disputa se reviste de la lógica judicial: "Propuso la Gloriosa palabra colorada, / 'Con esta alma, foles, - diz - non avedes nada; / mientre fue en el cuerpo fue mi acomendada, / agora prendrié tuerto por ir desamparada” (89).

Ahora bien, es en la disputa que se pone de relieve cómo pensar en el cuerpo supone atender a una cuestión de jurisdicciones. ¿Sobre quién recae el derecho y la obligación de atender a esa corporalidad y al alma con que forma una unidad? Y la contradicción se yergue en toda su locuacidad, pues desde su valencia inestable, cuerpo y alma - situados en el mismo plano (Weiss, 2006, p. 33) - se muestran merecedores de castigo, pero también de salvación. Como le responde el enviado diabólico a la Virgen: "Escripto es que el omne allí do es fallado / o en bien o en mal, por ello es judgado: / si esti tal decreto por ti fuere falssado, / el pleit del Evangelio todo es descuiado" (91). Pero, la lógica de la Virgen resulta implacable: "Fablas - diz la Gloriosa - a guis de cosa nescia, / no te riepto, ca eres una cativa bestia; / quando ixió de casa, de mí priso licencia, / del pecado que fizo yo.l daré penitencia" (92). Por medio de su ceremonia, el sacristán se había encomendado a la Virgen al salir del monasterio, de ahí que ella porte el derecho de ejecutar el castigo correspondiente a los malos actos que el cuerpo pecador había cometido - el mismo cuerpo que le había hecho servicio - .

Resulta elocuente el modo en que el cuerpo del sacristán, como hemos dicho, encarna la intermitencia. Desde una perspectiva distinta, pero coincidente con nuestra propuesta, Weiss revela esta tensión dialéctica en el mismo gesto del monje:

\footnotetext{
Of course, the motif of the genuflection and salutation ('el enclín e la Ave') is not original, but Berceo's version calls attention not only to the repetitive rituals of the monk's faith, but also - perhaps - to that phyisical movement that caracterizes his favourite vice, as the monk spends his days going in and out, up and down, impelled along his habitual path by what one might call the rhythms of luxuria. (2006, p. 34)
}

Expuesta la lógica, sucede el milagro, que desde nuestra perspectiva supone devolver las posesiones divinas a su justo lugar: el alma del sacristán vuelve a su cuerpo - " mandó tornar la alma al cuerpo el 
Sennor" (94c) - , liberando así al sacristán del mal usufructo demoníaco - "Contólis por su lengua toda la ledanía, / qué dizien los diablos e qué Sancta María; / cómo lo quitó ella de su podestadía” (97abc) - , hecho que hace que la conducta del sacristán, una vez resucitado, se re-encauce - "mejoróse de toda su mala contenencia" (99b) - , permitiendo así que el cuerpo devoto se dedique a su servicio, "mientre ovo potencia" (99c).

En lo que respecta al cuerpo del pecador y al mal usufructo que de él hace el diablo, el milagro "El romero engañado por el enemigo malo" mantiene la misma lógica que la del sacristán fornicario, aunque con un mayor grado de intensidad. La historia es conocida: Guiraldo, monje de Cluny, emprende su romería a Santiago de Compostela, solo que al igual que el sacristán fornicario comete un desliz sexual antes de salir, "en logar de vigilia yogó con su amiga" (185b). ${ }^{11}$

Aquello de interés, en este caso, es que este desliz de carácter sexual no sea, como en el milagro previamente analizado, la causa por la cual los diablos reclamarán el alma de Guiraldo una vez muerto, sino que se agrava al ahondar, más aun, en la fisicalidad. En efecto, habiendo emprendido el viaje, el diablo se le presenta al peregrino metamorfoseado como Santiago - "Transformóse el falso en ángel verdadero, / paróseli delante en medio un sendero" (188ab) - , y lo induce primero a mutilarse, y luego a caer en el suicidio: "Disso el falso Jácob: 'Esti es el judicio: / que te cortes los miembros que facen el fornicio; / dessent que te degüelles: farás a Dios servicio, / que de tu carne misma li farás sacrificio”" (192). Y Guiraldo, engañado, cumple con el pedido: "Crediólo el astroso, locco e desessado, / sacó su cuchellijo que tenié amolado; / cortó sus genitales, el fol malventurado: / dessende degollóse, murió descomulgado” (193).

Es pues el acto cometido por Guiraldo al suicidarse, previa emasculación, la que permite que el Diablo y sus secuaces se lleven el alma al infierno. En otras palabras, es el efecto que tiene en el cuerpo de Guiraldo el ejercicio de la voluntad del Maligno lo que como contrapartida directa supone que los diablos se lleven el alma del romero: "El que dio el consejo con sus atenedores, / los grandes e los chicos, menudos e mayores, / travaron de la alma los falsos traïdores, / levávanla al fuego, a los malos suores" (197). Y esta causa que justifica la soberanía demoníaca sobre el alma de Guiraldo, previa usurpación de su cuerpo humano comprendido como territorio, es la que Maligno esgrime con claridad al momento en que, para conservar "la preda" (199a), le espeta a Santiago: "Guirald fizo nemiga, matóse con su mano, / debe seer judgado por de Judas ermano; / es por todas las guisas nuestro parroquïano; / ¡Non quieras contra nos, Yago, seer villano!” (201). Porque, así como el Maligno se interpuso en el camino de Guiraldo para usufructuar mal su cuerpo, así también Santiago se interpone en el camino del Maligno para recuperar el alma y reestablecer la trayectoria del cuerpo caído en desgracia:

Ellos que la levavan
víolo Sanctīago
issiólis a grand priessa
paróselis delante

"Dessad —disso- maliellos la preda que levades, non vos yaz tan en salvo tenedla a derecho, creo que non podredes,

\section{non de buena manera,} cuyo romeo era; luego a la carrera, enna az delantera. (198) como vos lo cuidades; fuerza no li fagades, maguer que lo querades". (199)

Una vez más, pues, nos encontramos ante un problema de jurisdicciones en el que la cuestión central es a quién pertenece el cuerpo - y el alma - que se disputa: al Bien o al Mal. 
Santiago, no obstante, es claro acerca de la potestad que tiene sobre Guiraldo, comprendido como "mi romero":

$\begin{array}{ll}\begin{array}{l}\text { Dissoli Sanctiago: } \\ \text { Non vos puet vuestra parla } \\ \text { trayendo la mi voz } \\ \text { disti consejo malo, }\end{array} & \begin{array}{l}\text { valer un mal dinero; } \\ \text { como falsso vozero, } \\ \text { matest al mi romero. (202) }\end{array} \\ \text { Si tú no li dissiesses } & \text { que Sanctīago eras, } \\ \text { tú no li demostrasses } & \text { sennal de mis veneras, } \\ \text { non dannarié su cuerpo } & \text { con sus mismas tiseras, } \\ \text { nin yazdrié como yaze } & \text { fuera por las carreras. (203) } \\ & \\ \text { Prisi muy grand superbia } & \text { de la vuestra partida, } \\ \text { tengo que la mi forma } & \text { es de vos escarnida, } \\ \text { matastes mi romero } & \text { con mentira sabida, } \\ \text { demás veo agora } & \text { la alma maltraída. (204) }\end{array}$

Como bien expone Santiago, es la mentira del Maligno la que ha acabado con la vida del peregrino, por más que éste, en términos materiales, se haya degollado. Así lo entiende Santiago, y así lo entiende la Virgen quien hace que la contienda culmine a favor del santo: "Valió esta sentencia, fue de Dios otorgada, / fue la alma mesquina en el cuerpo tornada, /que pesó al dïablo, a toda su mesnada, / a tornar fo la alma a la vieja posada" (209).

De este modo, al igual que el sacristán fornicario, Guiraldo resucita; es decir que, por la gracia divina, es devuelto a la vida. Solo que, en este caso, el regreso es aún más espectacular dadas las condiciones de su muerte que quedan inscriptas en su cuerpo: 


\begin{tabular}{|c|c|}
\hline $\begin{array}{l}\text { Levantóse el cuerpo } \\
\text { alimpiava su cara } \\
\text { estido un ratiello como } \\
\text { como omne que duerme }\end{array}$ & $\begin{array}{l}\text { que yazié trastornado, } \\
\text { Guirald el degollado; } \\
\text { qui descordado, } \\
\text { e despierta irado. (210) }\end{array}$ \\
\hline $\begin{array}{l}\text { La plaga que oviera } \\
\text { abés parecié d'ella } \\
\text { perdió él la dolor } \\
\text { todos dizién: "Est omne }\end{array}$ & $\begin{array}{l}\text { de la degolladura } \\
\text { la sobresanadura; } \\
\text { e toda la cochura, } \\
\text { fue de buena ventura." (211) }\end{array}$ \\
\hline $\begin{array}{l}\text { Era de lo ál todo } \\
\text { fuera de un filiello } \\
\text { mas lo de la natura } \\
\text { non li creció un punto, }\end{array}$ & $\begin{array}{l}\text { sano e mejorado, } \\
\text { que tenié travesado; } \\
\text { quanto que fo cortado, } \\
\text { fincó en su estado. (212) }\end{array}$ \\
\hline $\begin{array}{l}\text { De todo era sano, } \\
\text { pora verter su agua } \\
\text { requirió su repuesto, } \\
\text { pensó de ir su vía }\end{array}$ & $\begin{array}{l}\text { todo bien encorado, } \\
\text { fincóli el forado; } \\
\text { lo que trayé trossado, } \\
\text { alegre e pagado. ( } 213 \text { ) }\end{array}$ \\
\hline
\end{tabular}

\author{
Levantóse el cuerpo \\ estido un ratiello como \\ como omne que duerme
}

La plaga que oviera
abés parecié d'ella
perdió él la dolor
todos dizién: "Est omne
Era de lo ál todo
fuera de un filiello
mas lo de la natura

\author{
que yazié trastornado \\ Guirald el degollado \\ cordado
}

de la degolladura

sobresanadura;

toda la cochura

e de buena ventura." (211)

sano e mejorado

quanto que fo cortado

fincó en su estado. (212)

fincóli el forado;
lo que trayé trossado,
alegre e pagado. (213)

Como puede apreciarse en las coplas citadas, una vez más el cuerpo se encarna en la intermitencia de una paradoja. Vehículo del pecado, es también vehículo de la salvación, en la medida en que es el cuerpo de Guiraldo el que testimonia a dos voces el pecado cometido y el milagro obrado. Como afirma Biaggini, literalmente Guiraldo "incarne les signes du miracle" (2007, p. 31), y "[l]es signes du péché se sont inversés pour devenir ceux du miracle" (Íbid.). Pero, lo realmente valioso desde nuestra perspectiva es que la imperfección de ese cuerpo rearmado nos devuelva un cuerpo que ante todo es una paradoja encarnada, espacio de pecado y salvación a un mismo tiempo.

Vale detenerse en un último ejemplo en el que el cuerpo pecador es acosado por el diablo. Aunque, sugestivamente, y a diferencia de los dos casos anteriores, aquí el enfrentamiento entre el Maligno y el Bien sí cobra, en detrimento de la lógica judicial, un carácter más material. Es el caso del bien conocido milagro de "El monje embriagado" que, como resume Berceo, "[...] cuntió en un monge de ábito reglar; / quísolo el dïablo durament espantar, / mas la Madre gloriosa sópogelo vedar" (461bcd). ${ }^{12}$

Todo comienza con el cuerpo debilitado del monje - podríamos incluso decir que débil vale tanto como decir bumano - , cuyo vicio no es de orden sexual, sino que se encuentra ligado a los placeres del paladar. En efecto, el monje sucumbe a los placeres del vino en la bodega del monasterio: ${ }^{13}$ "Entró enna bodega un día por ventura, / bebió mucho del vino, esto fo sin mesura, / embebdóse el locco, issió de su cordura, / yogó hasta las viésperas sobre la tierra dura" (463). Y este pecado del paladar pone de relieve la condición vulnerable del humano, cifrada en su cuerpo: 


\author{
Bien a ora de viésperas, \\ recordó malamientre, \\ issió contra la claustra \\ entendiéngelo todos
}

Peroque en sus piedes
iva a la eglesia
quísoli el diablo
ca bien se lo cuidava

\author{
el sol bien enflaquido, \\ andava estordido, \\ hascas sin nul sentido, \\ que bien avié bevido. (464)
}

\author{
non se podié tener, \\ como solié facer; \\ zancajada poner, \\ rehezmientre vencer. (465)
}

Como puede apreciarse, dada su embriaguez, el monje pasa todo el día tirado sobre el suelo de la bodega, para despertar aturdido y debilitado. Y esa debilidad tan propia del cuerpo humano, que supone cierta condición desvalida ante las fuerzas del Mal, se cifra en estos "piedes" sobre los cuales, titubeante en el paso, el monje "non se podié tener". En efecto, como señala Cacho Blecua (2003), dadas las condiciones físicas $-\mathrm{y}$ espirituales - del monje, el enfrentamiento contra las fuerzas del Mal resultará, evidentemente, muy desigual. Ante una presa tan fácil, no sorprende que el Diablo intente vencerlo, hacerlo tropezar, caer. Lo interesante es que no solo es por medio del cuerpo del monje embriagado y su debilidad constitutiva que se expresa una condición humana tan vulnerable y necesitada del apoyo divino, sino que, una vez más, lo que se pone en juego en el enfrentamiento es el cuerpo de este hombre del cual el Maligno se quiere apoderar. Y esta apropiación ilícita quedará expresada en cada uno de los tres ataques demoníacos bajo una lógica violenta y voraz. La crítica ya ha profundizado en el valor de las tres metamorfosis demoníacas, así como en los modos en que la Virgen obtura sus arremetidas. ${ }^{14}$ En breves palabras, el diablo arremete contra el monje en forma de toro, en forma de perro y, finalmente, en forma de león. ${ }^{15} \mathrm{Y}$ cada enfrentamiento se escalona en un in crescendo de virulencia física, que se corresponde también con el progreso en la trayectoria del monje, en su afán de llegar a la Iglesia. ${ }^{16}$ Así, habiendo salido de la bodega, el diablo se interpone en su camino en figura de toro, del mismo modo que había interceptado en su trayectoria a Guiraldo:

\begin{tabular}{|c|c|}
\hline $\begin{array}{l}\text { En figura de toro } \\
\text { cavando con los piedes, } \\
\text { con fiera cornadura, } \\
\text { paróseli delante }\end{array}$ & $\begin{array}{l}\text { que es escalentado, } \\
\text { el cejo demudado, } \\
\text { sannoso e irado, } \\
\text { el traïdor provado. (466) }\end{array}$ \\
\hline $\begin{array}{l}\text { Faciéli gestos malos } \\
\text { que li metrié los cuernos } \\
\text { priso el omne bueno } \\
\text { mas valió.l la Gloriosa, }\end{array}$ & $\begin{array}{l}\text { la cosa diablada, } \\
\text { por media la corada; } \\
\text { muy mala espantada, } \\
\text { reína coronada. (467) }\end{array}$ \\
\hline
\end{tabular}

La primera amenaza se resume, pues, en el espanto del monje embriagado y en la posibilidad de que su cuerpo sea desgarrado por los cuernos del toro enfurecido.

Ahora bien, llegando a las escaleras de la Iglesia, la segunda arremetida supone la transformación del Diablo en un perro, y la amenaza descansa de forma más patente en el terror de ser despedazado por sus dientes: 


\begin{tabular}{|c|c|}
\hline $\begin{array}{l}\text { Luego a poco rato, } \\
\text { ante que empezasse } \\
\text { cometiólo de cabo } \\
\text { en manera de can }\end{array}$ & $\begin{array}{l}\text { a poca de passadas, } \\
\text { a sobir ennas gradas, } \\
\text { con figuras pesadas, } \\
\text { firiendo colmelladas. (470) }\end{array}$ \\
\hline $\begin{array}{l}\text { Vinié de mala guisa, } \\
\text { el cejo muy turbio, } \\
\text { por ferlo todo pieças, } \\
\text { "Mesiello —dizié elli_- }\end{array}$ & $\begin{array}{l}\text { los dientes regannados, } \\
\text { los ojos remellados, } \\
\text { espaldas e costados, } \\
\text { graves son mis peccados". (471) }\end{array}$ \\
\hline
\end{tabular}

Finalmente, en el umbral de la Iglesia, el diablo acomete en forma de león. Y si en una primera instancia el peligro era que los cuernos desgarraran sus entrañas, y en un segundo momento ser por entero despedazado por los colmillos del rabioso can, ahora el peligro se cifra en ser completamente devorado:

$\begin{array}{ll}\begin{array}{l}\text { Entrante de la eglesia } \\ \text { cometiólo de cabo } \\ \text { en forma de león, } \\ \text { que trayé tal fereza }\end{array} & \begin{array}{l}\text { enna somera grada, } \\ \text { la tercera vegada, } \\ \text { una bestia dubdada, } \\ \text { que non serié asmada. (473) } \\ \text { Alli cuidó el monge } \\ \text { ca vidié por verdat } \\ \text { peor li era esto } \\ \text { entre su voluntat }\end{array} \\ \end{array}$

No cabe duda del rol fundamental que la Virgen desempeña a la hora de salvaguardar la integridad física del monje. En efecto, la Virgen se interpone entre éste y el acoso del Diablo en cada una de las tres embestidas. Pero lo que resulta más elocuente subrayar es cómo la Virgen devuelve a ese cuerpo debilitado - que no puede mantenerse en pie, y que ha padecido los ataques constantes del Maligno bajo la amenaza de su despedazamiento e ingestión - el bienestar y la protección: 


\begin{tabular}{|c|c|}
\hline $\begin{array}{l}\text { El monge que por todo } \\
\text { de la carga del vino } \\
\text { que vino e que miedo } \\
\text { que tornar non podió }\end{array}$ & $\begin{array}{l}\text { esto avié pasado, } \\
\text { non era bien folgado, } \\
\text { aviénlo tan sovado } \\
\text { a su lecho usado. (481) }\end{array}$ \\
\hline $\begin{array}{l}\text { La reína preciosa } \\
\text { prísolo de la mano, } \\
\text { cubriólo con la manta } \\
\text { púso·l so la cabeza }\end{array}$ & $\begin{array}{l}\text { e de precioso fecho } \\
\text { levólo pora'l lecho, } \\
\text { e con el sobrelecho, } \\
\text { el cabezal derecho. (482) }\end{array}$ \\
\hline $\begin{array}{l}\text { Demás, quando lo ovo } \\
\text { sanctiguó I con su diestra } \\
\text { "Amigo —disso·l_ fuelga, } \\
\text { con un pocco que duemas }\end{array}$ & $\begin{array}{l}\text { en su lecho echado, } \\
\text { e fo bien sanctiguado; } \\
\text { ca eres muy lazrado, } \\
\text { luego serás folgado. (483) }\end{array}$ \\
\hline
\end{tabular}

En efecto, la Virgen acompaña al monje embriagado hasta su lecho, y lo hace de la mano, para contrarrestar esa debilidad de los pies que no logran mantenerlo erguido. Pero no solo eso, sino que lo acuesta en su lecho, lo cubre y hasta le acomoda la almohada, para finalmente, con un último gesto de protección, santiguarlo y desearle un buen descanso.

Como señala Cazal (2000), en los Milagros, son muy pocos los casos en que el diablo se presenta de forma material ante los humanos para tentarlos. Estos podrían reducirse a los siguientes cuatro: "El sacristán fornicario", "El romero engañado por el enemigo malo", "El monje embriagado" y el milagro de "Teófilo". ${ }^{17}$ Como puede comprobarse en los tres casos analizados - así como en el de Teófilo, en el que también es posible corroborarlo-, el cuerpo del pecador es el eje rector sobre el cual se centra la disputa entre el Bien y el Mal, entendida en términos jurisdiccionales. Así, el diablo buscará por todos los medios usufructuar un espacio que no le corresponde, mientras que el orden celeste buscará salvaguardar esos cuerpos expuestos para reconducirlos al buen camino.

\section{INTEGRIDAD FÍSICA}

Como hemos visto, es el cuerpo del pecador el que está en el centro de la batalla entre el Bien y el Mal. No obstante, cabe decir que, en la disputa jurisdiccional de estas "posadas", otro cuerpo cobra relevancia: el de la misma Virgen. En efecto, tal como puede apreciarse en el milagro recién analizado de "El monje embriagado", es el cuerpo de la Virgen el que se interpone entre el débil pecador y el Maligno: "Vino Sancta María con ábito onrrado, / tal que de omne vivo non serié apreciado, / metióselis en medio a él e al Peccado, / el toro tan superbio fue luego amansado" (468). Y es en este gesto de la Virgen, el de proteger a los hombres, a la integridad física de los hombres, con su propio cuerpo, que se puede leer el gesto de su hijo, el "vero Salvador, /que por salvar el mundo sufrió muert e dolor" (487bc). En efecto, como pone de relieve Burke,

Berceo's Milagros is written to demonstrate the enormous power of the Virgin, in line with one of the principal aims of Catholic mariological theology since late antiquity, namely, to show that her life experience in many ways paralleled that of her Son. (1998, p. 132) 
Y esto queda constatado de modo literal por el mismo Berceo quien no duda en confirmar este paralelismo entre Madre e Hijo: "Las mannas de la Madre con las d'El que parió / semejan bien calannas qui bien las connoció; / Él por bonos e malos, por todos descendió, / Ella, si la rogaron, a todos acorrió" (159).

Ahora bien, entre estos muchos modos en que la Virgen opera como Jesús, encontramos, elocuentemente, el que salva con su cuerpo. ${ }^{18} \mathrm{Y}$ no solo en el caso del monje embriagado. Tanto en el milagro de "El judezno", como en el de "El parto maravilloso" y como en el de "El romero naufragado", la Virgen -asociada, generalmente, a su manto, como en el enfrentamiento contra el toro (Cacho Blecua, 2003) - logra la salvación humana al interponerse ella misma a modo de escudo ante el peligro.

En el primer caso, el del niño judío, la Virgen salvaguarda a la criatura que recién ha comulgado del castigo ígneo al que lo somete su padre furibundo homologado con el diablo: "Priso esti ninnuelo el falso descreído, / asín como estava, calzado e vestido, / dio con él en el fuego bravament encendido: / ¡mal venga a tal padre que tal faze a fijo!" (363). ${ }^{19}$ No obstante,

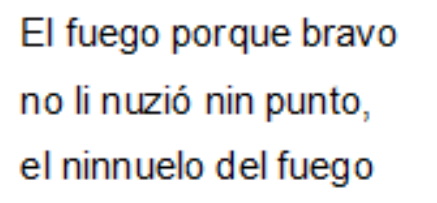

fizo un grand miraclo

Yazié en paz el ninno
en brazos de su madre
non preciava el fuego
ca.I fazié la Gloriosa

Issió de la foguera

non sintió calentura

non priso nulla tacha,

ca pusiera en elli

\begin{abstract}
fue de gran cosiment, mostróli buen talent; estorció bien gent,
\end{abstract}

el Rey omnipotent. (365)

en media la fornaz, non yazrié más en paz, más que a un rapaz, companna e solaz. (366)

sin toda lissión, más que otra sazón; nulla tribulación, Dios la su bendición. (367)

La escena resulta pictórica: tras la lectura de las cuadernas citadas es posible entrever dentro del horno al pequeño judío en brazos de la Virgen, rodeados por las llamas e intactos. En efecto, la imagen del cuerpo de la Virgen protegiendo al pequeño se alimenta con la comparación materna - "en brazos de su madre non yazrié más en paz" - , así como con el modo en que el pequeño tiene de identificarla: "La duenna que estava enna siella orada / con su fijo en brazoz sobre'l altar posada, / éssa me defendié que non sintié nada" (369bcd). ${ }^{20}$

Si en el caso de "El judezno" el elemento principal es el fuego, en el caso de "El parto maravilloso" y "El romero naufragado", es el agua. Tal como lo narra su beneficiaria, en el caso de "El parto maravilloso", el milagro es doble: 


\begin{tabular}{|c|c|}
\hline $\begin{array}{l}\text { Quando vi que de muert } \\
\text { que de las fieras ondas } \\
\text { comendéme a Christo } \\
\text { ca pora mí consejo }\end{array}$ & $\begin{array}{l}\text { estorcer non podía, } \\
\text { circundada sedia, } \\
\text { e a Sancta María, } \\
\text { otro non entendia. ( } 447 \text { ) }\end{array}$ \\
\hline $\begin{array}{l}\text { Yo en esto estando, } \\
\text { cubrióme con la manga } \\
\text { non sentía nul periglo } \\
\text { si yoguiesse en vanno }\end{array}$ & $\begin{array}{l}\text { vino Sancta María, } \\
\text { de la su almexía; } \\
\text { más que quando dormía, } \\
\text { más leida non sería. (448) }\end{array}$ \\
\hline $\begin{array}{l}\text { Sin cuita e sin pena, } \\
\text { parí este fijuelo, } \\
\text { Ovi buena madrina, } \\
\text { fizo misericordia }\end{array}$ & $\begin{array}{l}\text { sin ninguna dolor, } \\
\text { igrado al Criador! } \\
\text { non podría mejor, } \\
\text { sobre mí, peccador. (449) }\end{array}$ \\
\hline $\begin{array}{l}\text { Fizo en mi grand gracia, } \\
\text { si por ella non fuesse, } \\
\text { valióme en el parto, } \\
\text { nunqua mugier non ovo }\end{array}$ & $\begin{array}{l}\text { non una ca doblada, } \\
\text { sería enfogada, } \\
\text { si non, sería dannada, } \\
\text { madrina tan onrrada. (450) }\end{array}$ \\
\hline
\end{tabular}

En efecto, la Virgen no solo salva a la mujer preñada de ahogarse, sino que, en medio de las aguas, habilita un parto sin daño y sin dolor. Y si bien es este segundo milagro por el que se conoce el poema, cabe centrarse en la explicación que da la parturienta de cómo se salva de ser ahogada. Así como el niño judío es salvado del fuego en el abrazo protector de la Virgen, la mujer embarazada salva su vida gracias a que la Virgen la cubre "con la manga de la su almexía", interponiendo su propio manto entre el cuerpo de la mujer y las aguas del mar. Como señala Burke, " $t \mathrm{t}]$ his idea of the Virgin as protective cover returns time and again throughout the Miracles" (1998, p. 121). Tal es así, que en "El romero naufragado" asistimos a un caso muy similar. Tal como explica el náufrago salvado por la Virgen: 


\author{
Quando de la grand nave \\ ca parecié por ojo \\ vedia que de muerte \\ '¡Valme Sancta Maria!'
}

\section{Dissi esta palabra: \\ Non podí más dizir \\ fue luego ella presta \\ si non fuesse por ella}

\section{Luego fo ella presta, \\ panno era de precio, \\ echómelo de suso, \\ cuenta que te domisti}

quisifuera salir,

que se querié somir,

non podia guarir:

empecé a decir. (607)

\author{
'¡Valme Sancta Maria!' \\ ca vagar non avía; \\ por su placentería, \\ enfogado sería. (608)
}

adusso un buen panno,

nunqua vid su calanno;

disso 'Non prendrás danno,

o que yoguist en vanno.' (610)

Resulta interesante cómo las palabras de la Virgen recuerdan ora al caso del monje embriagado, a quien arropa mientras duerme - "cubriólo con la manta e con el sobrelecho" (482c) - y a quien había defendido del toro, "con la falda del manto" (469a), ora el caso del parto maravilloso, en el que se menta el placer de un buen baño. ${ }^{21}$

Las cuadernas siguientes estarán, pues, dedicadas al manto de la Virgen, cuya descripción recuerda aquella sobre la sombra de los árboles del prado del "Prólogo alegórico", la cual, como expresa Orduna, “cobija a todos los hombres, religiosos y seglares - como en las representaciones de la plástica, en que el manto de la Virgen es refugio seguro de vasallos y señores - [...]" (1967, p. 450): "Feliz será la alma e bienaventurada, / que so tan rica sombra fuere asolazada; / nin frío nin calura nin viento nin elada / non li fará enojo que sea embargada" (611).

Vale la pena detenernos en un último caso para ilustrar el valor que cobra el gesto de la Virgen que, al igual que su hijo, pone el cuerpo en pos de la salvación de los hombres. Nos referimos al milagro de "El ladrón devoto", en donde ya no son ni el fuego ni el agua los elementos amenazantes, sino en cierto modo el aire. ${ }^{22}$ En efecto, el milagro trata sobre un ladrón apresado por la justicia y enjuiciado a la horca: "Levólo la justicia pora la crucejada, / do estava la forca por concejo alzada; / prisiéronli los ojos con toca bien atada, / alzáronlo de tierra con soga bien tirada" (147).

Lo interesante desde nuestra perspectiva es que la brevedad del milagro realza la gracia de la Virgen, la cual interpone su propio cuerpo para salvar de la muerte al ladrón, no una sino dos veces. Así, la primera, supone salvarlo de la horca, para lo cual le ofrece sostén al hombre con sus propias manos, impidiendo que la horca se accione por el propio peso del cuerpo: "Metióli so los piedes do estava colgado / las sus manos preciosas, tóvolo alleviado: / non se sintió de cosa ninguna embargado, / non sovo plus vicioso nunqua nin más pagado" (150). Al tercer día, cuando los familiares van en busca del cuerpo: ${ }^{23}$ "Trobáronlo con alma alegre e sin danno, / non serié tan vicioso si yoguiesse en vanno; / dizié que so los piedes tenié un tal escanno, / non sintrié mal ninguno si colgasse un anno" $(152) .^{24}$

No obstante, la justicia lejos de comprender el milagro sospecha haber sido engañada, con lo cual se acuerda degollarlo, lo que permite que, por segunda vez, la Virgen se interponga entre el daño mortal y el cuerpo del 
ladrón: "Fueron por degollarlo los mancebos más livianos, / con buenos seraniles grandes e adïanos; / metió Sancta María entre medio las manos, / fincaron los gorgueros de la golliella sanos" (155).

Cazal señala respecto de este milagro que "[a] unque la Virgen prescinde de aparecer verdaderamente, su presencia se inscribe visualmente «en hueco» en el espacio de los hombres” (2000, p. 93). No obstante, cabe decir con mayor énfasis que, aunque no se vean, son las manos de la Virgen las que se interponen entre la garganta del ladrón y las sierras, son sus manos las que elevan el cuerpo del condenado a la horca, y es en ese hueco, espacio invisible, que se inscribe un cuerpo salvador.

\section{Cuerpo COMO Testimonio}

Una vez considerado el cuerpo en su relación con el acoso del Mal - siendo el diablo la figura del Mal por antonomasia -, así como en su vínculo con las fuerzas del Bien - encarnadas en la Virgen que intercede y salvaguarda la integridad física de los pecadores al interponer su propio cuerpo-, cabe finalmente reflexionar acerca de la corporeidad del pecador en sí misma, como el espacio en el que se inscribe el milagro. Pues, como podremos observar a continuación, en más de una ocasión es el milagro el que se inscribe en el cuerpo, y con él se identifica.

Para comenzar, cabe decir que en los umbrales de la colección hallamos dos milagros referidos a un castigo: "La casulla de San Ildefonso" al inicio y "La iglesia despojada" hacia el final. ${ }^{25} \mathrm{Y}$ si bien nos detendremos en aquellos que comportan una recompensa en lugar de un castigo, resulta elocuente subrayar cómo en ambos casos referidos el castigo impacta en la zona corporal en la que se cifra el des-servicio a la Virgen. En efecto, en el caso del milagro primero, el arzobispo que sucede a San Ildefonso comete el error de igualarse con su predecesor, pronunciando "unas palavras de muy grand liviandat" (69a) y vistiendo la casulla obsequiada por la Virgen, la cual, como esta deja bien en claro, únicamente al "cuerpo sennero" (63b) de San Ildefonso le es otorgado vestirla. ${ }^{26}$ Siagrio, nos dice Berceo, habría tenido que retener su lengua, pero al haberse equiparado con el santo, la casulla celeste "prísoli la garganta como cadena dura, / fue luego enfogado por la su grand locura" (72cd).

Por su parte, en "La iglesia despojada", no es la garganta la parte del cuerpo afectada, sino la mano con la que el clérigo ladrón osa despojar a la Virgen de la pequeña iglesia de su toca: "Luego que de la toca travó el malfadado, / pegóseli tan firme en el punno cerrado / que con englut ninguno no serié tan travado, / nin con clavo que fuesse con martiello calcado" (719). ${ }^{27}$ Como puede observarse, en ambos casos el milagro opera a modo de deíctico: señala y al mismo tiempo denuncia el desvío, por medio de una marca corporal.

Ahora bien, muchos más numerosos son los casos en que el milagro se inscribe en el cuerpo no como castigo, sino como recompensa. Ejemplo claro de ello son los milagros en que el cuerpo resucita, como en los casos ya vistos de "El sacristán fornicario" y de "El romero engañado por el enemigo malo". Tanto en uno como en otro, el regreso a la vida de aquel que se pensaba muerto opera desde una doble valencia: como milagro efectivo y como testimonio material de ese mismo milagro. Y es que, resulta consabido que solo puede haber milagro en la medida en que haya un testigo. En otras palabras, no es suficiente con que haya un beneficiario: para que el milagro sea tal, debe haber un otro que dé testimonio del mismo. Y he aquí, que este testimonio será dado por el cuerpo.

El milagro de "Los dos hermanos" y el de "La iglesia Gloriosa profanada" son dos casos que ilustran con breve claridad cómo el poema resuelve por medio del cuerpo la cuestión central del testigo milagroso. En el primer caso, Esteban, un avaro regidor, logra tras su muerte, gracias a una cadena de intercesiones, resucitar durante el plazo de treinta días para poner sus cosas en orden. Lo interesante es que, para hacerlo, debe dirigirse al Papa, a quien le ofrece la historia de todo lo experimentado tras su muerte. Pero he aquí que las palabras, el relato solo, no bastan. Es necesario algo que opere como garante de lo que se dice, algo que avale la verdad de la historia. Y esta verdad se inscribe en el propio cuerpo, a modo de testimonio: "Demostrava 
el brazo que tenié livorado, / en el que Sant Laurent lo ovo apretado, / pidié merced al Papa con el cuerpo prostrado" (265abc). En efecto, al morir, Esteban es interpelado por el enojo de San Lorenzo, a quien con sus “judicios falsos" (240a), "tollióli tres casares" (240b): "Víolo San Laurencio, católo feamientre, / primió.l en el brazo tres vezes duramientre; / quessóse don Estevan bien entro en el bientre, / no.l primiren tenazas de fierro tan fuertmientre" (242). Y es justamente el cuerpo amoratado de Esteban, con las secuelas de su encuentro con San Lorenzo, el que se ofrece como testimonio del milagro acaecido.

En el segundo caso, una vez más el cuerpo se expone, junto a sus secuelas, como garante de veracidad del milagro acaecido, del milagro narrado. Tres hermanos profanan una iglesia dedicada a la Virgen, al matar allí dentro a un hombre que buscaba protección. Ante tal ofensa a la Virgen, un fuego infernal es enviado por Dios, a modo de castigo: "Con esta majadura eran muy maltrechos, / perdién piedes e manos e fincavan contrechos, /las piernas e los brazos bien cerca de los pechos, / iva Sancta María prendiendo sus derechos" (386).

No obstante, los hermanos logran salvarse gracias a la piedad mariana, y rectificar su trayectoria vital tras confesarse ante el obispo y hacer penitencia. Pero, este milagro no circularía si uno de los hermanos no lo hubiese compartido, y más aún certificado con su propio cuerpo:

Contólis a los uéspedes
cómo enna eglesia
cómo Sancta María
e cómo se perdieron

Teniendo que su dicho

delante muchos omnes demostrólis un fierro

cinto a la carona,

Podié aver en ancho
era cerca del fierro
la que yacié de yuso
fuése end otro día

Fiziéronse los omnes ca udién fuertes dichos, doquier que se juntavan d'esso fablavan todos, toda su aventura, fizieron desmesura, ovo d'ellos rencura, de mala calentura. (406)

no li serié creído, tollióse el vestido, que trayé escondido, correón desabrido. (407)

quanto media palmada, la carne muy inchada; era toda quemada, de buena madrugada. (408)

todos maravillados, vedién miembros dannados, mancebos o casados, mozo e ajumados. (409)

Solo después de que el cuerpo en el que se encarna el milagro se ofrece como testimonio, el relato puede acceder al escrito: "Fue luego est miraclo escripto e notado, / por amor que non fuesse en oblido echado, / cogieron mucho miedo de facer tal peccado, / de quebrantar eglesia e logar consegrado" (410). Y es que, como explica Bynum: 
[1]a idea ampliamente compartida de que los cuerpos no sólo reflejan la gloria que sus almas reciben en presencia de Dios, sino que son también el lugar donde las personas son recompensadas o castigadas en su especificidad sirve de soporte para muchas historias hagiográficas y exempla de este período en el que la incorruptibilidad u otros signos milagrosos afectan solamente a una parte del cuerpo. (1990, pp. 200-201)

Y, cabe decir que, así como en el caso de "El monje embriagado", la marca física que denuncia el pecado cometido expresa en simultáneo el milagro vivido.

Es en "El clérigo y la flor", no obstante, el poema en el que la identificación entre cuerpo y milagro es total. Ante todo, cabe decir que el protagonismo del cuerpo en este milagro resulta patente desde el momento en que la cuestión central recae en el sitio en el que el cuerpo de este clérigo es sepultado. Por haber muerto fuera de la villa, y sin que la gente supiese cómo, el cuerpo del clérigo devoto de María es enterrado "defuera de la villa entre unos riberos", "non entre los dezmeros" (104cd). Y esto entristece a la Virgen, pues el cuerpo de su siervo no se encuentra en el lugar que le corresponde, es decir, en espacio sagrado. De ahí que la Virgen se presente, y dé las indicaciones necesarias para corregir el error: "["]Mándote que lo digas: que el mi cancellario / non merecié seer echado del sagrario; / dilis que no lo dexen ý otro trentanario, / métanlo con los otros en el buen fossalario.' "(107).

Sucede que, como se lee en la copla citada y como expresa Berceo, se sabe que el cuerpo del clérigo "Bien avié treinta días que era soterrado / en término tan luengo podié seer dannado" (106ab). En efecto, como hemos remarcado en más de una ocasión, lo propio del cuerpo humano es su finitud: su materia inestable lleva consigo la marca de su propia caducidad. En otras palabras, la materia se degrada; en su imperfección, se descompone. De ahí que, habiendo pasado treinta días, evidentemente los clérigos vayan a encontrar un cuerpo en estado de descomposición. No obstante, ese cuerpo humano debe ocupar el espacio que le corresponde, en el cementerio, y es por esta razón que, siguiendo el pedido de la Virgen, debe ser trasladado: "[']El que vos soterraste luenne del cimiterio, / al que vos non quisiestes fazer nul ministerio, / yo por ésti ti fago todo est reguncerio: / si bien no lo recabdas, tente por en lazerio.” (110). La importancia que tiene el lugar en el que yace el cuerpo tras la muerte no resulta inocente, y ensalza esa materialidad que, a pesar de su constitutiva caducidad, conforma una compleja unidad con el alma, junto a la cual comparecerá el día del juicio final.

Finalmente, los clérigos van en busca del cuerpo, y al abrir la sepultura "vidieron un miraclo non simple ca doblado" (111c):

Issiéli por la boca

de muy grand fermosura, inchié toda la plaza

que non sentién del cuerpo una fermosa flor

de muy fresca color;

de sabrosa olor,

un punto de pudor. (112)

tan fresca e tan sana

la fermosa mazana;

a la meridiana

en media la quintana. (113)

Como puede apreciarse, ambos milagros competen por entero al cuerpo del difunto, al punto tal de que se inscriben en él. De un lado, la hermosa flor que sale de la boca del clérigo, como antes lo hiciera su saludo a la Virgen, impide que el olor del cuerpo putrefacto se sienta. Evidentemente, por ser el cuerpo de un hombre, tras treinta días, la descomposición hará que hieda. No obstante, el milagro florido irradia en el espacio que ocupa el cuerpo un sabroso perfume que anula el "pudor". Del otro, a pesar de la humanidad de ese 
cuerpo muerto, la lengua permanece fresca y sana, ajena a cualquier tipo de corrupción. Así pues, si en los dos primeros milagros abordados, el milagro operaba sobre la parte del cuerpo específica en la que se cifraba el des-servicio; aquí, en cambio, el milagro se expresa en toda su elocuencia, en la boca y la lengua del clérigo, con las que saludaba a la Virgen, exclamando su nombre. Como señala Weiss, "Berceo elaborates upon the basic motif of the beautiful flower, wich symbolizes the continuous and redeeming presence of the Virgin on the sinner's tongue" (2006, p. 40).

Vale la pena, no obstante, hacer una precisión, para lo cual resulta sugestivo recordar aquellas flores del prado del "Prólogo alegórico", que no son otras que los nombres de la Virgen. Pues, son ellas las que, en cierto sentido, permiten entrever que el cuerpo muerto del clérigo, yaciente en la sepultura, aún se encuentra pronunciando - por siempre jamás - el nombre de la Virgen, que sale de su boca en forma de perfumada flor. De ahí que su lengua se encuentre fresca, más aún que cuando hablaba en vida, pues en un acto de eternidad el clérigo continúa saludando a la Virgen desde su tumba. ${ }^{28}$

Así pues, el milagro de "El clérigo y la flor" expresa con sugestiva literalidad la potencia del cuerpo entendido como vehículo hacia lo trascendente, "como instancia de comunicación de un universo abstracto que se hace perceptible a través de él” (Balestrini, 2000, p. 270); e, incluso, como espacio en el que se inscribe el mismo milagro.

\section{Corolario}

Abordar la obra de Berceo supone situarse ante los textos del "primer poeta castellano de nombre conocido" (Deyermond, 1999, p. 109). Y pensar en su figura convoca de forma ineludible una coyuntura no exenta de tensiones que se inscribe al interior de sus textos. En efecto, en la primera mitad del siglo XIII es posible registrar una serie de procesos sociales y culturales que se imbrican en la obra del poeta riojano. Pensar en Berceo es pensar en la expansión cultural urbana que habilita la posibilidad de un nuevo actor social, el clérigo letrado; es atender al pasaje que va de los monjes insertos en redes de monasterios como agentes de la cultura elevada a los clérigos seglares insertos en las escuelas catedralicias, germen de las universidades. A su vez, si en Berceo, en tanto clérigo seglar, se intersecta el mundo monástico y el mundo urbano, en él también se cifra el pasaje que va del latín al uso de una lengua vulgar - el castellano - como lengua de cultura, y la conjunción de elementos provenientes de la tradición culta, así como de una tradición de raigambre popular.

Por otro lado, la obra de Berceo reclama no ignorar la peculiaridad de las nuevas formas de devoción, ligadas a una vertiente piadosa más afectiva, centrada en los aspectos más humanos de la divinidad, que encuentra en la noción de proximidad, de cercania, una de sus claves interpretativas. De este modo, el orden trascendente se humaniza: el culto a la Virgen María se desarrolla exaltando su humanidad; un nuevo tipo de santidad, fundamentada en la imitatio Christi, se gesta; santos noveles comienzan a surgir por todo el Occidente europeo; mientras que el demonio, comprendido como la encarnación del mal, se muestra como una presencia latente y material, que gravita en el día a día de los hombres, situados entre las fuerzas del Bien y el Mal.

En este contexto, en que la batalla entre el Bien y el Mal opera como marco de comprensión, la pregunta por lo humano y, más específicamente, por su cuerpo nos llevó a la consideración del hombre pecador, cuyo cuerpo humano es comprendido como el territorio que estas fuerzas se disputan.

Así pues, los Milagros de Nuestra Señora permiten hacer foco en el cuerpo del pecador, como un espacio en peligro que se buscará salvaguardar. En efecto, si hay algo que ilustran los Milagros es que no solo la salvación del alma supone una preocupación fundante, sino también la salvación del cuerpo, ese territorio permanentemente disputado entre las fuerzas del Bien y el Mal. Lo interesante aquí es que el cuerpo del pecador pone de relieve lo que es entendido como un problema de jurisdicción. El diablo busca por todos los medios usufructuar un espacio que no le corresponde, mientras que el orden celeste busca salvaguardar esos cuerpos expuestos para reconducirlos al buen camino. De ahí que el cuerpo humano se caracterice por su 
intermitencia: vehículo del pecado, es también vehículo de la salvación. De hecho, la importancia que supone proteger el cuerpo humano cobra un relieve tal que incluso la Virgen en más de una ocasión, en un gesto homologable al de su Hijo, interpone su propio cuerpo para garantizar la salvación del pecador. Finalmente, cabe destacar cómo el cuerpo del pecador termina por configurarse como testimonio del milagro acaecido o, incluso, se eleva al nivel en el que la identificación entre cuerpo y milagro es total. De este modo, es posible constatar algo que no deja de intuirse en ninguna de las obras de Berceo, y es que en sus poemas, el cuerpo es un territorio en disputa.

En última instancia, cabe decir que el cuerpo humano es, en el sentido más cabal, una posesión divina, un territorio sagrado. Y este cuerpo que puede ser mal usufructuado por el Diablo, también puede ser mal usufructuado por los mismos hombres. Un buen uso del cuerpo, no obstante, es posible, lo que lo convierte en una vía de acceso al orden trascendente. En su ejemplo más radical, están las trayectorias santas, de fuerte impronta corpórea. Pero, también, existen ejemplos más modestos, pero no por ello menos elocuentes, en la medida en que, gracias a una sincera invocación, el cuerpo de un simple clérigo puede encarnarse en milagro.

\section{REFERENCIAS}

Alarcos Llorach, E. (1992). La lengua de las obras de Berceo. En I. Uría Maqua (Ed.), Obra Completa (pp. 13-27). Madrid: Espasa-Calpe y Gobierno de la Rioja. Recuperado a partir de: http://www.vallenajerilla.com/berceo/a larcosllorach/lenguaobrasberceo.htm

Alvar, M. (1992). Gonzalo de Berceo como hagiógrafo. En I. Uría Maqua (Ed.), Obra Completa (pp. 29-59). Madrid: Espasa-Calpe y Gobierno de la Rioja. Recuperado a partir de: http://www.vallenajerilla.com/berceo/berceoha giografo.htm

Balestrini, M. C. (2000). Entre la aflicción y la gloria: cuerpo e ideología en las vidas de santos de Gonzalo de Berceo. En Actas del VIII Congreso Internacional de la Asociación Hispánica de Literatura Medieval (pp. 269-278). España: Santander.

Baños Vallejo, F. (1997). ‘Teófilo’ y 'La iglesia robada’ (¿o a la inversa?). El final de los Milagros de Nuestra Señora de Gonzalo de Berceo. En J. M. Lucía Mejías (Ed.), Actas del VI Congreso Internacional de la Asociación Hispánica de Literatura Medieval (pp. 243-256). Alcalá de Henares: Universidad de Alcalá

Baños Vallejo, F. (2003). Las vidas de santos en la literatura medieval española. Madrid: Ediciones del Laberinto.

Benito-Vessels, C. (2003). Gonzalo de Berceo, el sacristán fornicario, la abadesa encinta y las Dueñas de Zamora. Revista de Poética Medieval, 10, 11-24.

Berceo, G. de (ed. M. Gerli, [1985] 2006). Milagros de Nuestra Señora. Madrid: Cátedra.

Biaggini, O. (2007). 'Todos somos romeos que camino pasamos': homo viator dans le mester de clerecía. Cahiers d'études hispaniques médiévales,30, 25-54.

Boreland, H. (1983). Typology in Berceo's Milagros: The Judiezmo and Abadesa Preñada. Bulletin of Hispanic Studies, 60, 15-29.

Burke, J. F. (1998). Desire Against the Law. The Juxtaposition of Contraries in Early Medieval Spanish Literature. California: Stanford University Press.

Bynum, C. W. (1990). El cuerpo femenino y la práctica religiosa en la Baja Edad Media. En M. Feher, R. Naddaff y N. Tazi (coords.), Fragmentos para una bistoria del cuerpo humano (pp. 163-225). Madrid: Taurus.

Cacho Blecua, J. M. (2003). La ambivalencia de los signos: el «monje borracho» de Gonzalo de Berceo (Milagro XX). En Walde Moheno, L. von der (Ed.), Propuestas teórico-metodológicas para el estudio de la literatura hispánica medieval (pp. 107-149). México: Universidad Autónoma Nacional de México-Universidad Autónoma Metropolitana.

Cazal, F. (2000). Características y articulación del espacio del mundo terrenal y del espacio del más allá en los Milagros de Nuestra Señora. En F. Crosas (Ed.), La fermosa Cobertura. Lecciones de Literatura Medieval (pp. 71-100). Pamplona: Universidad de Navarra (Publicaciones de Literatura Española, 16). 
Cid, A. C. (1981). El milagro del ladrón devoto de Gonzalo de Berceo y su relación con la fuente latina: De fure suspenso quem beata virgo liberavit. Letras, 1, 23-29.

Deyermond, A. (1975). Berceo, el diablo y los animales. En Homenaje al Instituto de Filología y Literaturas Hispánicas "Dr. Amado Alonso" en su cincuentenario 1923-1973 (pp. 82-90). Buenos Aires.

Deyermond, A. (1999). Historia de la literatura española 1. La Edad Media. Barcelona: Ariel.

Diz, M. A. (1995). Historias de certidumbre: los Milagros de Berceo. Newark, Delaware: Juan de la Cuesta.

Dutton, B. (1964). Gonzalo de Berceo: unos datos biográficos. En Actas del I Congreso de la Asociación Internacional de Hispanistas: celebrado en Oxford del 6 al 11 de septiembre de 1962 (pp. 249-254).

Dutton, B. (1968). La profesión de Gonzalo de Berceo y el manuscrito del Libro de Alexandre. Berceo, 80, 285-294.

Dutton, B. (1978). "La fecha del nacimiento de Gonzalo de Berceo". Berceo, 94-95, 265-268.

Dutton, B. (Ed.) (1980). Los "Milagros de Nuestra Señora” de Gonzalo de Berceo. Londres: Támesis.

Funes, L. (2009). Investigación literaria de textos medievales: objeto y práctica. Buenos Aires: Miño y Dávila.

García de la Concha, V. (1992). La mariología en Gonzalo de Berceo. En I. Uría Maqua (Ed.) Obra Completa (pp. 61-87). Madrid: Espasa-Calpe y Gobierno de la Rioja. Recuperado a partir de: http://www.vallenajerilla.com/ berceo/garciadelaconcha/mariologiaberceana.htm

Gerli, M. (1985). La tipología Bíblica y la introducción a los Milagros de Nuestra Señora. Bulletin of Hispanic Studies, 62, 7-14.

Gerli, M. ([1985] 2006). Introducción. En Milagros de Nuestra Señora (pp. 11-53). Madrid: Cátedra.

Gómez Moreno, A. (1988). Clerecía. En C. Alvar y A. Gómez Moreno (Eds.), La poesía épica y de clerecía medievales (pp. 71-153). Madrid: Taurus.

Hamlin, C. (2015). ¿Sobre yelo escrives?: el protagonismo de lo escrito (y otras lecturas metapoéticas) en los milagros 'La casulla de Ildefonso' y 'Teófilo' de Berceo. Incipit, 35, 71-102.

Hamlin, C. (2018). La configuración tipológica de 'La abadesa preñada' de Berceo y su relación con la tradición apócrifa. Revista de Filología Española, 2(98), 371-396.

Koch, J. (2019). Malos huéspedes en buenas posadas: figuraciones y funciones del demonio en la Vida de San Millán de la Cogolla, de Gonzalo de Berceo. Rivista di storia e letteratura religiosa, 1(55), 3-50. Italia: Leo S. Olschki Editore.

Le Goff, J. (1995). El hombre medieval. En J. Le Goff(Ed.), El hombre medieval (pp. 9-44). Madrid: Alianza.

Lida de Malkiel, M. R. (1941). «Estar en (un) baño, estar en un lecho de rosas». Revista de Filología Española, 3, 263-270.

Muñoz-Basols, J. (2004) ‘ ¡Mal venga a tal padre que tal faze a fijo!’ La agresión corporal como representación alegórica de la fe cristiana en los Milagros de Nuestra Señora. Atenea, 1(24), 47-57.

Orduna, G. (1967). La introducción a los Milagros de Nuestra Señora de Berceo. El análisis estructural aplicado a la comprensión de la intencionalidad de un texto literario. En Actas del Segundo Congreso de la Asociación Internacional de Hispanistas (Nimega, 1965) (pp. 447-456). Nimega: Instituto Español de la Universidad de Nimega.

Rico, F. (1985). La clerecía del mester. Hispanic Review, 53, 1-23 y 127-150.

Snow, J. (1982). Gonzalo de Berceo and the Miracle of Saint Ildefonso: Portrait of the Medieval Artist at Work. Hispania, 1(65), 1-11.

Uría Maqua, I. (1981). Sobre la unidad del Mester de Clerecía del siglo XIII: Hacia un replanteamiento de la cuestión. En Actas de las IIIJornadas de Estudios Berceanos (pp. 179-188). Logroño, España: Instituto de Estudios Riojanos.

Uría Maqua, I. (2000). Panorama crítico del “mester de clerecía”. Madrid: Castalia.

Weiss, J. (2006). The "Mester de clerecia": Intellectuals and Ideologies in Thirteenth-Century Castile. Woodbridge: Tamesis. 
Wilkins, H. (1999-2000). El judío y el diablo como otro en los Milagros de Nuestra Señora de Berceo. Letras: Revista de la Facultad de Filosofia y Letras de la Pontificia Universidad Católica Argentina Santa María de los Buenos Aires, 40-41, 13-18.

\section{Notas}

1 Para una aproximación más acabada de esta materia, remitimos a los trabajos insoslayables de Rico (1985), Gómez Moreno (1988) y Uría Maqua (1981a y 2000). Mientras que Uría ofrece un trabajo fundacional sobre la estética de la “cuaderna vía" y en su trabajo panorámico hace hincapié en la consideración del "mester de clerecía” en tanto escuela poética; Rico y Gómez Moreno ofrecen su contextualización, en tanto "versión española, inequívoca, de esa escuela de dimensiones europeas” (Rico, 1985, p. 4). Respecto de la lengua de las obras de Berceo, ver Alarcos Llorach (1992), quien afirma que "la lengua de Berceo se ajustaba a lo que podemos suponer propio del habla castellanizada de La Rioja del siglo XIII, en la cual perduraban algunos fenómenos orientales", pero que "se ajusta a una norma en esencia castellana, a la cual se suman las particularidades ennoblecedoras que aportan los latinismos y, en definitiva, su calidad de clérigo bien impuesto en la erudición de la época”.

2 Como señala Funes, “[c]uando Gonzalo de Berceo dice: 'Quiero fer una prosa en román paladino / en qual suele el pueblo fablar con so vecino, / ca non so tan letrado por fer otro latino, / bien valdrá, como creo, un vaso de bon vino’ se está plantando ante una tradición milenaria y está apostando por una escritura nueva, por hacer de esa lengua cotidiana un instrumento de expresión artística. Esa osadía y su fortuna es lo que podemos legítimamente admirar y es lo que el hispano-medievalismo busca investigar" (2009, p. 44). En efecto, nos situamos ante "una generación de espíritus inquietos, hace ocho siglos, gente joven e impertinente que se quería comer el mundo [y que] decidió recoger de la calle las palabras de todos los días, las palabras despreciadas por la alta cultura, las que escuchaban en sus casas desde la cuna, y con esas palabras se atrevieron a componer obras de arte verbal usando las técnicas y los recursos aprendidos de la literatura latina" (Íbid.).

3 En efecto, el trabajo realizado por el hispanista británico marcó un punto de inflexión en las consideraciones acerca del poeta riojano, de quien, en el decir de Alvar, puede predicarse "[c]ualquier cosa menos sencillez e ingenuidad" (1992). Para profundizar al respecto remitimos a los ya clásicos trabajos de Dutton (1964, 1968 y 1978).

4 Para una aproximación atenta al rol demoníaco en la configuración de la santidad en la Vida de San Millán de la Cogolla ver Koch (2019).

5 Para María como canal de gracia divina, sirvan a modo de ilustración, como ejemplos puntuales, las cuadernas 32-41 del "Prólogo alegórico", entre las cuales destacamos la 35, "Ella es dicha fuent de qui todos bevemos, / ella nos dio el cevo de qui todos comemos; / ella es dicha puerto a qui todos corremos, / e puerta por la qual entrada atendemos"; así como también la copla 624, "Ella que es de gracia plena e avondada, / guíe nuestra fazienda, nuestra vida lazrada, / guárdenos en est mundo de mala sorrostrada, / gánenos en el otro con los sanctos posada. (Amén)”. En cuanto a la imagen de abogada y cobijadora de la humanidad, resultan elocuentes las palabras que Teófilo le dirige en su ruego de las coplas 835-845, de las cuales destacamos la 848: "Sennora benedicta entre todas mugieres, / bien lo querrá tu Fijo lo que tú bien quisieres; / todo te lo dará lo que tú bien pidieres, / a mí verná la carta si tú savor ovieres”.

6 Como explica Gerli en el apartado introductorio a su edición, "[n]inguno de estos dos manuscritos corresponde exactamente al texto de Berceo, puesto que en ellos falta la fuente de su Introducción, y el de la Biblioteca Nacional carece de la de los milagros de la Iglesia despojada (XXIV) y el de Teófllo (XXV). El manuscrito de Copenaghe ofrece una variación mínima frente al texto de nuestro poeta y es, por tanto, el más próximo, si no idéntico, al que utilizó Berceo. En él se sigue el mismo orden de las historias en los milagros I-XV, y en la narración de los siguientes el mismo esquema fuera del caso de cuatro milagros. Por su parte, Berceo parece haber añadido una anécdota, la de la Iglesia despojada (XXIV de nuestra edición) que no figura en ninguna de las posibles fuentes latinas que han sobrevivido” (2006, p. 26).

7 Cabe destacar que el "Prólogo alegórico" que oficia como umbral de acceso a la colección de milagros ha sido objeto de profundo interés por parte de la crítica. Así pues, ha sido abordado desde la perspectiva de su originalidad y sus fuentes; así como también, desde una aproximación tipológica, atenta a su elaboración figurativa. Sobre esta labor crítica, destacamos, por una parte, el trabajo de Dutton (1980) y por otra, los trabajos de Orduna (1967) y de Gerli (1985).

8 Para las citas de Berceo hemos utilizado Milagros de Nuestra Señora, ed. Michael Gerli, Madrid, Cátedra ([1985] 2006). Al final de las mismas y entre paréntesis se indicará el número de estrofa correspondiente.

9 Para una aproximación diversa, ver Carmen Benito-Vessels (2003), quien aborda las conexiones del milagro con la actualidad local zamorana de mediados del siglo XIII.

10 Cabe decir que por construirse en base a un pecado de carácter sexual, el milagro de "La abadesa preñada" también puede vincularse con la casuística del sacristán. No obstante, dado que Berceo omitió en su traducción toda referencia demoníaca que justificase el pecado, no lo incluiremos dentro de estas consideraciones. 
11 Como señala Biaggini, este milagro "fait référence à une réalité péninsulaire qui concerne au premier chef une communauté monastique comme San Millán de la Cogolla qui pouvait accueillir des pèlerins et constituer une étape dans leur voyage jusque'au tombeau de l'Apôtre. Le récit, dont on conserve de nombreuses versions en Espagne et dans le reste de l'Europe, se teinte donc d'une connotation locale forte" (2007, pp. 29-30).

12 El milagro en el que esta lógica judicial sí se mantiene es aquel de "El labrador avaro". No obstante, en este enfrentamiento, les basta a los ángeles con esgrimir ante los diablos el nombre de la Virgen para salir victoriosos. Cabe destacar, a su vez, cómo este breve milagro enfatiza la lógica jurisdiccional del cuerpo comprendido como espacio: "Levantóse un ángel, disso: 'Yo so testigo, / verdat es, non mentira esto que yo vos digo: / el cuerpo, el que trasco esta alma consigo, / fue de Sancta María vasallo e amigo. // Siempre la ementava a yantar e a cena, / diziéli tres palabras: 'Ave gratä plena’; / la boca por qui essié tan sancta cantilena / non merecié yazer en tan mala cadena" (277).

13 Resulta consabida, como remarca Cacho Blecua (2003), la asociación entre la ebrietas y el demonio.

$14 \mathrm{Al}$ respecto, ver Deyermond (1975) y Cacho Blecua (2003).

15 Deyermond (1975) ha sabido subrayar que la aparición conjunta de estos tres animales no resulta inocente, y ya se encuentra en el Salmo 21.

16 Resulta elocuente cómo Cazal homologa la trayectoria del monje embriagado con un via crucis: "penoso recorrido [...] desde la bodega del convento a su cama, pasando por la iglesia, recorrido en el que cae tres veces asaltado por visiones horroríficas del demonio" (2000, p. 77).

17 Para un abordaje del milagro de Teófilo en línea con nuestra interpretación, remitimos a Hamlin (2015), quien pone en evidencia la relación de identidad entre la carta, el alma y el cuerpo de Teófilo, todos tres salvados por la Virgen al recuperar el escrito del fuego del infierno.

18 Para subrayar el que la Virgen aparezca, en muchos aspectos, como un equivalente de su hijo, Burke esgrime el ejemplo del milagro de "Teófilo": "The miracle of Theophilus establishes that Mary acomplished the second action referred to in the Inlation, the descent to hell, another powerful equivalence to the life of her Son” (1998, p. 140).

19 Boreland (1983) subraya, siguiendo a Dutton, cómo el padre retratado por Berceo es conscientemente maligno en su accionar. Desde esta perspectiva, no solo cabe recordar a los perseguidores de San Lorenzo, quienes intencionadamente buscan ofrecer el mayor suplicio posible al mártir - recordemos que tanto en este caso, como en aquel, el fuego es el vehículo del castigo-, sino que, al igual que en el caso de San Lorenzo, lo que pareciera ponerse en acto es la crucifixión (Boreland, 1983: 18). Por el otro lado, cabe decir que la crítica ha analizado la figura del judío en concomitancia con la del diablo. Al respecto, ver Wilkins (1999-2000), así como también Weiss, quien afirma: "The Spanish poet conflates the father with the Devil in part in order to underscore the opposition between Christianity, wich is aligned with the natural, the loving, and the rational, and Judaism, wich is aligned with the unnatural, the unforgiving, and the irrational" (2006, p. 58). "It is not that he is completely devoid of reason, but that his logic is brutal and perverse. Other sinners in Berceo's world may be tricked by te Devil, but here he actually inhabits the body of this particular jew. As such, the jewish father, like de Devil, represents a fallen nobility and a perverted order (but order nonetheless), but he also epitomizes all that is foul and physically repulsive — ' fazié figuras malas' - all that needs to be exorciced" (Íbid.). Por su parte, Diz (1995) comprende este milagro desde la perspectiva que le ofrece el proceso judicial de la ordalía.

20 Desde una perspectiva diversa, la agresión corporal sufrida por el niño judío también ha sido estudiada por MuñozBasols (2004).

21 Ver Lida de Malkiel (1941).

22 Ver Cid (1981) para un cotejo del milagro con su fuente.

23 Gerli ([1985] 2006) remarca en su edición, ante la precisión temporal, el deseo de Berceo de trazar un paralelo entre la resurrección del ladrón y la de Cristo en el tercer día después de su ejecución, explotando así las posibilidades tipológicas del relato.

24 Como puede observarse, resulta frecuente en Berceo la homologación del baño a una situación placentera. Al respecto, ver, como especificamos para el caso de "El romero naufragado" y "El parto maravilloso" en la nota 21, Lida de Malkiel (1941).

25 Acerca del debate sobre cuál ha de ser el milagro final de la colección, "Teófilo" o "La iglesia despojada", coincidimos con Hamlin cuando señala que la discusión "es en sí irresoluble, pues se basa en un intento de llegar a una 'voluntad de autor' única, que la misma tradición manuscrita desmiente (2015, p. 73). Cabe destacar, a su vez que, como señala Baños Vallejo (1997), en ambos milagros es posible encontrar elementos que avalen su posición final, debido a que los dos han sido concebidos como cierre de la colección en distintos momentos.

26 Como señala sugestivamente Hamlin, habría una relación de identidad entre el cuerpo del santo y la casulla obsequiada por la Virgen: "La casulla [...] textualiza, es decir, encarna en la forma de un tejido, su santidad. De esta manera, la relación de identidad entre vestidura santa/cuerpo santo en tanto continente y contenido (o corteza y meollo) sería análoga a la que se establece entre la escritura (continente) y su referente (contenido) en tanto verdad" (2015, p. 85).

27 Para una aproximación a "La casulla de San Ildefonso" remitimos a Snow (1982). 
28 Si bien no profundizaremos al respecto, cabe decir que el milagro de "La abadesa preñada" también resulta elocuente en lo que respecta al cuerpo como espacio de inscripción milagrosa. En efecto, al igual que en "El clérigo y la flor", en el caso de la abadesa preñada, su cuerpo también deviene testimonio literal del milagro. Solo que, sugestivamente, el cuerpo de la abadesa se ofrece como el reverso de los casos analizados en la medida en que, el milagro radica justamente en que, tras la intervención de la Virgen, no haya en él señal alguna de maternidad. Para una aproximación a este caso, remitimos a la labor de Boreland (1983), Diz (1995), Benito-Vessels (2003), Weiss (2006) y Hamlin (2018). 